\title{
Étienne Vitelli, Commentaires sur la guerre civile de France (1567)
}

\section{Dario Cecchetti}

\section{(2) OpenEdition \\ 1 Journals}

\section{Edizione digitale}

URL: http://journals.openedition.org/studifrancesi/30078

DOI: 10.4000/studifrancesi.30078

ISSN: 2421-5856

Editore

Rosenberg \& Sellier

\section{Edizione cartacea}

Data di pubblicazione: 1 avril 2006

Paginazione: 141

ISSN: 0039-2944

\section{Notizia bibliografica digitale}

Dario Cecchetti, «Étienne Vitelli, Commentaires sur la guerre civile de France (1567)», Studi Francesi [Online], 148 (XLX | I) | 2006, online dal 30 novembre 2015, consultato il 18 avril 2021. URL: http:// journals.openedition.org/studifrancesi/30078; DOI: https://doi.org/10.4000/studifrancesi.30078

Questo documento è stato generato automaticamente il 18 avril 2021.

\section{(c) (i) (9)}

Studi Francesi è distribuita con Licenza Creative Commons Attribuzione - Non commerciale - Non opere derivate 4.0 Internazionale. 


\title{
Étienne Vitelli, Commentaires sur la guerre civile de France (1567)
}

\author{
Dario Cecchetti
}

\section{NOTIZIA}

ÉTIENNE VITELLI, Commentaires sur la guerre civile de France (1567), édition et traduction par ANNE LOMBARD-JOURDAN en collaboration avec MARC H. SMITH, Paris, École des Chartes, 2005, pp. 143.

1 Viene qui offerta la pubblicazione di un inedito conservato nella Bibliothèque Municipale di Saint-Denis. Si tratta di una cronaca, scritta in latino col titolo Commentariorum de bello civili Gallico pars prior, opera di un ignoto ecclesiatico italiano, Étienne Vitelli, che insegnò a Parigi giurisprudenza ed eloquenza. Essa racconta le peripezie della lotta che oppone cattolici e protestanti durante i mesi di settembre, ottobre e novembre 1567 (dall'imboscata di Meaux alla battaglia di Saint-Denis). La data di redazione è situabile fra la fine del 1567 e la morte del cardinale Vitellozzo Vitelli (19 novembre 1568), cui la cronaca è dedicata. L'interesse dell'inedito è di offrire anzitutto il punto di vista di un italiano (che pure parla della Francia come della propria patria) sulla guerra civile e di religione che sconvolge il paese che lo ospita, e di arricchire pertanto la documentazione di origine italiana su questo periodo (si pensi soprattutto alle relazioni di viaggio e ai rapporti degli ambasciatori veneziani). L'interesse del manoscritto è accresciuto dal fatto che Vitelli ha accompagnato il suo testo con una pianta di Parigi e degli schieramenti opposti alla battaglia di Sain-Denis, opera del cosmografo ed antiquario André Thevet, che permette di confrontare il discorso cronachistico con una documentazione cartografica - commentata anch'essa accuratamente dagli editori - che aiuta la ricostruzione storica. Il testo latino è accompagnato da una traduzione francese a fronte. 